\title{
The Nature of Primary Vocal Tremor
}

\author{
V. C. HACHINSKI, I. V, THOMSEN AND N. H. BUCH.
}

SUMMARY: Three elderly women with marked progressive voice tremor, without other neurological symptoms, and negative family histories were investigated.

All had a 4-5 $\mathrm{Hz}$ respiratory tremor in expiration and, to a lesser degree, in inspiration; and all had vocal tremulousness synchronous with their respiratory irregularity. Articulation of phonemes was normal. In two cases the neurological examination was otherwise normal; in the third case there was a minimal $71 / 2$

RÉSUMÉ: Trois femmes d'un certain âge avec un tremblement marqué progressif de la voix, sans autres symptômes neurologiques, et dont l'histoire familiale est négative furent investiguées.

Toutes trois présentaient un tremblement respiratoire à l'expiration de 4-5 $\mathrm{Hz}$ et, à un degré inférieur, également à l'inspiration; toutes manifestaient un tremblement vocal synchrone avec leur irrégularité respiratoire. L'articulation des phonèmes était normale. Dans deux cas, l'examen neurologique était normal; dans le troisième cas, il y avait un
$\mathrm{Hz}$ tremor in the left thumb and index finger.

Simultaneous speech and vocal air pressure recordings, as well as cinematographic studies of the vocal apparatus and diaphragm were carried out.

It is suggested that these cases represent primarily an action tremor of respiration, that they belong in the spectrum of essential tremor, and hence may be amenable to treatment with propranolol.

tremblement de $7 \frac{1}{2} \mathrm{~Hz}$ dans le pouce et l'index gauches.

Des enregistrements simultanés de la parole et de la pression d'air vocale, ainsi que des études cinématographiques de l'appareil vocal et du diaphragme sont rapportés.

Il est suggéré que ces cas représentent surtout un tremblement d'action à la respiration, qu'ils appartiennent au spectre du tremblement essentiel, et donc qu'ils peuvent répondre à un traitement au propanolol.
From the Departments of Neurology and Otolaryngology, Bispebjerg Hospital and Rigshospitalet, University of Copenhagen, Denmark.

Reprint requests to Dr. V. C. Hachinski, MacLachlan Stroke Unit, Sunnybrook Hospital and University of Toronto Clinic, 2075 Bayview Avenue, Toronto, Ontario, Canada M4N 3M5.

Dr. Hachinski was supported by an Ontario Department of Health Feilowship.

Presented in part at the 9th Canadian Congress of Neurological Sciences, Saskatoon, June 22nd, 1974
Voice disorders are not uncommon with neurological disease. Cerebellar disturbances, extrapyramidal disorders and palatal myoclonus can all cause abnormal speech modulation. However, cases with voice tremor as the presenting symptom or indeed the only symptom, are relatively rare.

The purpose of this report is to review 3 such cases, to suggest that they represent a disorder of respiration, that they belong in the spectrum of essential tremor and hence may be amenable to treatment with propranolol.

\section{Case No. 1}

\section{CASE REPORTS}

This 69-year-old woman had been admitted to Bispebjerg Hospital three years previously because of back pain radiating into the legs and difficulty walking. At the same time she noted a tremor of her voice. All the other symptoms disappeared within months but the marked voice tremor slowly worsened. On examination the patient exhibited a marked irregular tremor of her voice. Expiration and to a lesser degree inspiration were also interrupted irregularly. Phonemes were articulated correctly and the neurological examination was otherwise normal. Examination included a search for palatal and other myoclonus and attempts to elicit any latent tremor of the upper limbs by having the patient hold heavy objects with her fingers with arms outstretched.

Case No. 2

A 72-year-old woman, she had noted gradual onset of a voice tremor four years before. Despite speech therapy the tremor progressed until the patient was socially disabled. On examination the patient had a marked irregular tremor of her 
voice with a similar interruption of inspiration, expiration and phonation. The rest of the eurological examination was norm. No limb tremor could be detecid on repeated examinations.

\section{Case No. 3}

This 67-year-old woman had a sudden onset of voice tremor two years previously. On examination she had an irregular tremor of respiration, phonation and speech. The neurological examination was normal except for a latent tremor of the patient's left index finger and thumb that could be elicited by having the patient hold a heavy object between them.

None of the patients had a family history of tremor nor of neurologic disease. Case No. 3 suffered from classical migraine and had a family history of the same.

\section{SPECIAL INVESTIGATIONS}

Case No. 1.

Phoniatric Evaluation

Direct examination of the nose, mouth, pharynx and larynx revealed no abnormalities. Stroboscopic examination was normal.

Fundamental frequency $210 \mathrm{~Hz}$

Voice range $\quad 128-493 \mathrm{~Hz}$

Vocalization time 15 seconds

Pulmonary Function Tests

Normal.

Audiocinematography

Fluoroscopy of the patient's diaphragm with simultaneous voice recordings were carried out. While the patient held her breath the diaphragm did not move. Towards the end of inspiration slight irregular up and down jerky movements occurred synchronous with the interruption of breathing. During expiration, phonation (aaah) and speech, the interruption of the normally smooth downward movement of the diaphragm became increasingly pronounced.

Aerometry and Voice Oscillography By using an Electroaerometer Type EA 510/8, tracings of the air pressure during breathing were obtained. The patient showed interruption of inspiration but particularly expiration at about $4 \mathrm{~Hz}$

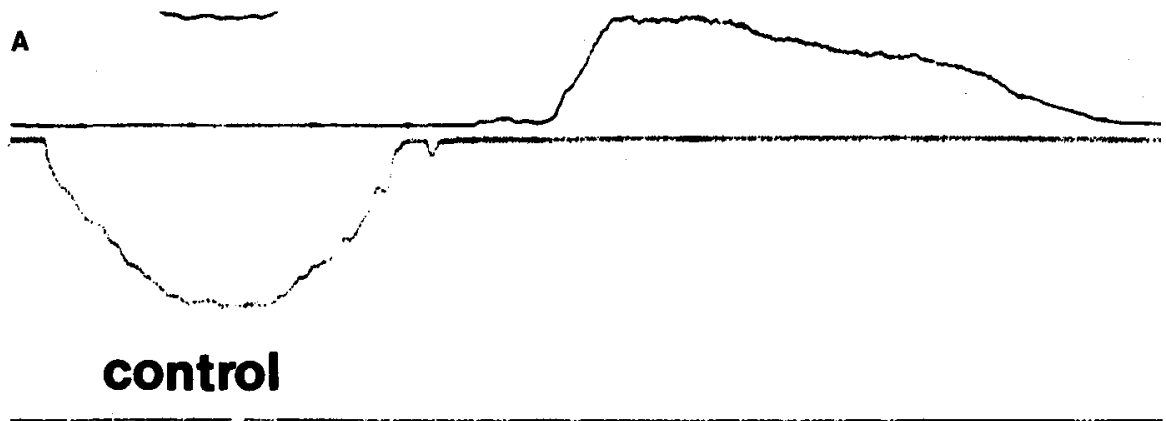

B

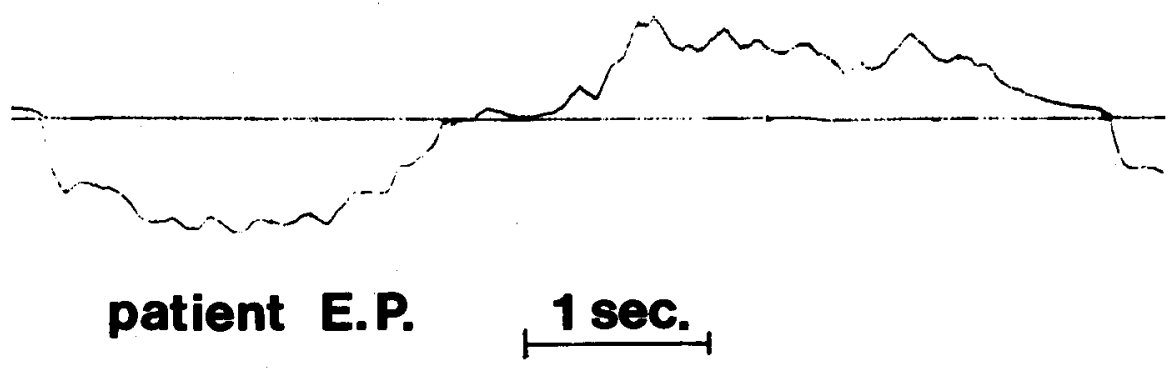

Figure 1-Tracings of air pressure during inspiration (valley) and expiration (crest) in a normal control (a) and in Case No. 1 (b).

(Fig. 1b) Fig. 1a shows the tracing from a normal control. Simultaneous oscillograms of the patient's expiration and phonation (aaah) showed irregularities and actual interruption of breathing and sound production (Fig. 2b). This is in marked contrast with the smooth tapering of the expiration and phonation tracing of a normal control (Fig. 2a).

\section{Case No. 2}

Phoniatric Evaluation

Direct visual and stroboscopic examination of the vocal apparatus was normal.

Fundamental frequency $230 \mathrm{~Hz}$

Voice range $\quad 146-512 \mathrm{~Hz}$

Vocalization time 13 seconds

Pulmonary Function Tests

Mild obstructive pattern.

Audiocinematography

Inspiration, expiration, phonation and speech produced an increasing tremor of the vocal apparatus and diaphragm. There were no abnormal movements when the patient held her breath.

Aerometry and Voice Oscillography

Demonstrated an irregular tremor of respiration and vocalization at $5 \mathrm{~Hz}$.
Case No. 3

Phoniatric Evaluation

Visual and stroboscopic examination of the vocal organs was normal.

Fundamental frequency $200 \mathrm{~Hz}$

Voice range

$11 / 2$ octaves

Vocalization time 9 seconds

Respiratory Function Tests

Normal.

\section{Audiocinematography}

Fluoroscopy of the patient's vocal apparatus and diaphragm showed no abnormal movements when the patient held her breath. In order of intensity: Inspiration, expiration, phonation and speech produced an irregular tremor of the vocal apparatus and the diaphragm.

Aerometry and Voice Oscillography correlated with finger tremor

By having the patient hold a balloon connected to a transducer between her left thumb and index finger a tracing of her finger tremor was obtained. Simultaneous recording of her voice while saying "aaah" showed the voice tremor to be slower than the finger tremor $\left(4 \frac{1}{2}\right.$ and $7 \mathrm{~Hz}$ respectively). 


\section{DISCUSSION}

The patients studied were elderly and without any family history of voice tremor. To characterize their symptom as "senile voice tremor" would not be precise nor allow for the fact that voice tremor of varied etiology can occur in the senium. Furthermore the voice tremor was the only symptom in otherwise healthy individuals who did not accept this as an expected concomitant of aging and sought medical help.

Case No. 3 had a latent tremor of the left thumb and index finger; in the absence of voice tremor this would have been attributable to benign essential tremor. Brown and Simonson (1963) found that 6 of their 31 cases of organic voice tremor had no limb or head tremor; they suggested that organic voice tremor was a disorder of phonation and a manifestation of essential tremor. Our clinical, audiocinematographic, aerometric and oscillographic studies suggest further that monosymptomatic vocal tremor is primarily an action tremor of respiration. We found no tremor when the patients held their breath; there was an increasing tremor with expiration, phonation and speech. In Case No. 3 the voice tremor was slower than the finger tremor, but it is well recognized that the basic frequency of a tremor is modified by the anatomical site of its occurrence. Marshall (1968).

The efficacy of propranolol in action limb tremor (Winkler and Young, 1974) provides a rationale for the treatment of the respirovocal variety.

\section{ACKNOWLEDGEMENTS}

We wish to thanks Drs. J. Bjerrum, N. A. Lassen and E. Skinj jj from the Departments of Radiology, Clinical Physiology and Neurology, Bispebjerg Hospital and Mr. B. Frokjaer-Jensen M.A., from the Institute of Phonetics, University of Copenhagen, for helping us with our investigations.

A

\section{EXPIRATION}

\section{OSCILLOGRAM}

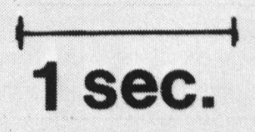

B

\section{EXPIRATION}

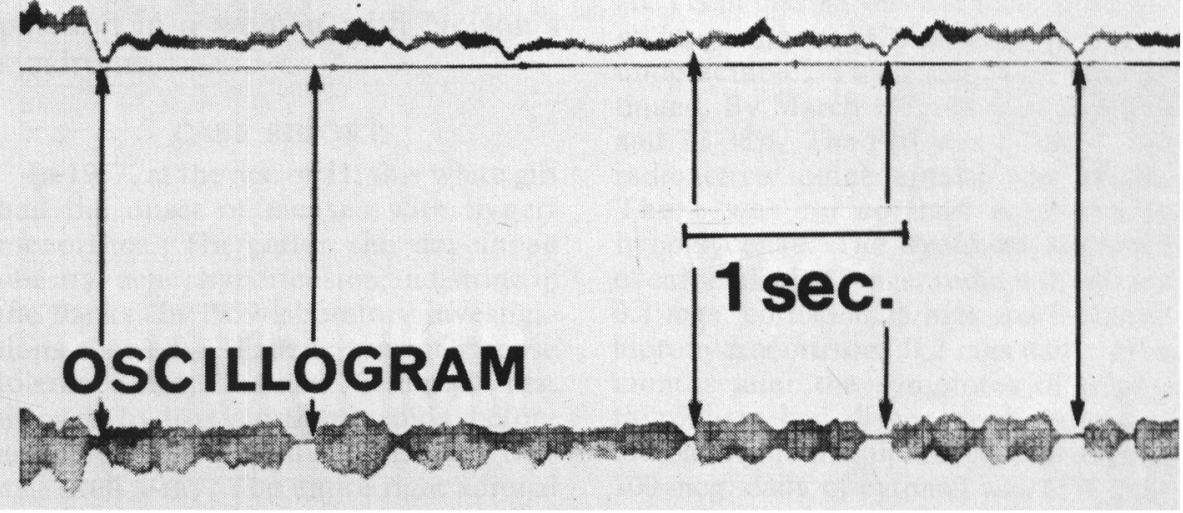

Figure 2-Simultaneous tracing of expiration and phonation (oscillogram) while saying "aaah" in a normal control (a) and in Case No. 1 (b). In the latter irregularities in respiration largely correspond to changes in the voice including actual stoppages (arrows).

\section{REFERENCES}

BROWN, J. R. and SIMONSON, J. (1963). Organic voice tremor. Neurology (Minneap.) $13,520-525$.

MARSHALL, J. (1968). Tremor, in Vinken P. J. and Bruyn, G. W., (Eds.) Handbook of Clinical Neurology. Amsterdam,
North-Holland Publishing Company, Vol. 6, pp. 809-825.

WINKLER, G. F. and YOUNG, R. R. (1974). Efficacy of chronic propranolol therapy in action tremors of the familial, senile or essential varieties N. Engl. J. Med. 290, 984-988. 